\title{
Industry Clusters: an Antidote for Knowledge Sharing and Collaborative Innovation?
}

\author{
Professor Julia Connell, and A/Professor Michael Thorpe, \\ Curtin Business School, Curtin University, Perth, Australia.
}

\begin{abstract}
This paper will focus on Industry Clusters and a rationale for why they may be considered an Antidote for Knowledge Sharing and Collaborative Innovation. The paper draws on data gathered during the course of research undertaken in Dubai.
\end{abstract}

\section{INTRODUCTION}

Industry clusters are defined as geographical concentrations of interconnected companies and institutions that gain performance advantages through their co-location (Porter, 1998). Also referred to as networks and industrial districts, regions that possess strong clusters are recognised as better performing. This is mostly as a result of the opportunities they create for building the competitive advantage of firms in an increasingly globalised world where small and medium sized firms are under growing pressure to compete internationally, and where it is easier for firms and value-chains across an industry to relocate and to integrate (Solvell et al, 2003). Industry clusters are seen as integral to the development of knowledge economies based around innovation, which can be viewed as an interactive process characterised by knowledge flows and information sharing between various economic agents. As innovation is multi-faceted and difficult for individual firms to exploit (Bessant, 2004), clusters can provide a mechanism to manage the process more effectively as geographically concentrated firms, that are linked or networked to various degrees are said to help drive innovation and the creation, diffusion, application and commercialisation of new knowledge (OECD, 2007).

An effective innovation system is said to comprise business, consultants and research institutions that keep pace with new knowledge and technology while assimilating and adapting it to local needs, thus facilitating its diffusion and foreign sourcing can be critical in this area. Hence, industry clusters, which provide strong local and global business networks that are regionally and globally oriented with broad linkages, can be viewed as an integral part of this process, providing mechanisms for firm interaction (Ewers and Malecki, 2010) and the achievement of greater competitive advantage (Simmie, 2008).

Specifically, this paper will address the industry cluster development experiences in Dubai in order to analyse the question posed in the title of this paper through the following sub-questions:

1. Why clusters as the antidote for growth and innovation?

2. What has been the approach to cluster development in Dubai?

3. What can cluster facilitators do to enhance knowledge sharing and collaborative innovation?

\section{Why Clusters?}

Watson (2011) maintains that there are few economic development policies as popular as clusters, given it is difficult to find a country, region, or even a city that is not trying to develop a network of complementary and competitive firms. He points out the appeal of clusters from a political perspective, given the global economic crisis has highlighted the need for innovation in order to diversify economies and create jobs. Thus, industry clusters reportedly have a dual purpose. One being to enhance the competitiveness of the SMEs that comprise them, by utilizing the advantages generated by business cooperation and agglomeration economies and the other to build or revitalise certain regions.

A cluster may be differentiated by specialisation in terms of some stage along the value chain (e.g. logistics, media or marketing) or may focus on selected customer needs or market segments (e.g. health, information technology, financial services or education) (Ketels, 2003). Firms within a cluster exhibit some complementarity and this may relate to the nature of their products or services, the inputs that they employ, the suppliers of these inputs or the skill sets of employees (Swann et al., 1998). Related collaborators and service providers (including 
universities, professional associations, standards agencies, training companies etc.) as well as customers may also co-exist within the cluster.

A particular element which characterises a cluster is the interconnectedness or the linkages between the various parties. It is this aspect that allows firms to create value and improve competitive advantage through leveraging off the potential strengths of the group and the exploitation of agglomeration economies. The resulting agglomeration economies or spatial externalities help foster the competitive advantage of participating firms in cluster groupings (Motoyama, 2008).

Cluster strategies have become important forms of economic development in recent years. In a world economy where small and medium sized firms are under increasing pressure to compete internationally, clusters are increasingly seen as being an integral part of sustainable regional development strategies (OECD, 2005: Montana and Neneide, 2008; Yusuf, 2008). With technological change being so rapid and its impact so pervasive, and with the enhanced ability of firms and whole value-chains to integrate and relocate globally, activities located within strong performing clusters and regions with strong clusters are recognised as creating greater opportunity for building global competitive advantage (Solvell et al, 2003; OECD, 2001). This can occur through gains from knowledge sharing and cooperation among other factors.

Recognition of the role that clusters can play in regional development is reflected in initiatives supported by international organisations such as the OECD and the World Bank (Motoyama, 2008). For example, the Local Economic Development (LED) programme of the World Bank is aimed at helping local communities build sustainable economic capacity and has the establishment of business clusters a an integral component (World Bank, 2009). Sectors for assistance and support are targeted based on their identified potential for long-term success. The aim is not to pick winning clusters, but for policy makers and other agents to build on a region's inherited resources in order to create differentiated and distinctive areas of economic activity. Growing clusters of firms rather than just focusing on individual firms is seen as less costly in terms of resources, less distorting than firm-specific approaches and more targeted than economy-wide measures (Ketels, 2003). Martin et al (2008) observe that national governments in many countries have been heavily involved in promoting clusters over the past two decades. Evidence of this is widely seen in Eastern Europe, East Asia and South America (Parrilli, 2007; Yusuf et al, 2008; OECD, 2005).

Arino et al (2001) maintain that regardless of the size, form, or objectives of a cluster, one factor that serves to distinguish them from other forms of inter-firm behaviour is the need to establish relationships between the parties. Further, they propose that the quality of relationship enjoyed by parties within the cluster will depend upon the degree to which those parties have come to rely on trust in their dealings. The intensification of resource sharing and inter-partner learning within Clusters makes trust between members even more crucial (Madhok, 1995), which is why inter-party trust plays an important role within successful clusters (Luo, 2002). The rationale is that, when Cluster members have high levels of trust in each other, they will be more likely to be committed to, and persist with, knowledge sharing and thus build social capital. Solvell et al (2003) propose that; while physical capital can travel the world, as can human capital to some extent, it is the social capital embedded in local cultures and institutions that is enhanced in the cluster environment that provides the network for collaboration and potential for innovation. Social capital is defined as networks, relationships and institutions with shared understandings and values that facilitate co-operation among stakeholders, with trust being an important element (Ionescu, 2005). Thus, the quantity and quality of these interactions and exchanges both have value and create value (Persson et al, 2006). Trust has become a central concept in the study of inter-organizational collaboration (Lane and Bachman, 1998). Increasing numbers of writers point out that trust is the foundation of any collaborative effort (Arino et al, 2001; Howarth et al, 1995, Lynch, 1993) and thus will be discussed in more detail in the next section.

\section{KNOWLEDGE SHARING, TRUST, COLLABORATION AND INNOVATION}

A global CEO study (2006) identified that external collaboration was indispensible, with business partners and customers cited as the key 
source of innovative ideas. However, the study also identified that their organizations were not collaborating enough and that innovation needed orchestration from the top.

Business today is based on networks within and between organisations. As a result, knowledge spill-overs are important. Knowledge needs to flow between individuals, groups and firms in different locations, as well as within companies, in order to be used effectively. Therefore, it is important to ascertain what type of knowledge is valuable for innovators and imitators and how is that knowledge transferred? New approaches have become necessary for sharing the value created in collaborative ventures and promoting innovation. Porter's (2003) definition of innovation includes improvements in technology and better methods of doing things. Information is a major factor in the process and may be a resource that is not available to competitors, or something that is interpreted in new ways. This is where knowledge clusters can play an important role. Porter states that innovation can result from organisational learning as well as research and development, but that it always involves investment in developing skills and knowledge and sometimes physical assets and marketing efforts as well.

Two types of cluster can be identified: technology based and know-how based (such as education and training). Although firms cluster because of the perceived advantages of being located near similar or related firms, the benefits must be weighed against the costs arising from increased competition for resources and customers. Forms of competition and cooperation have led to creation of the term 'coopetition' which is often used by practitioners and researchers alike to refer to the co-existence of both cooperative and competitive behaviours exhibited by industry cluster firm members. Wilheim (2011) points out that, co-opetition researchers like to think of it as a distinct research paradigm that is said to go beyond the traditional cooperative paradigm, as it does not view competition as something to be reduced or balanced in order to make the positive outcomes of cooperation possible. Further, she points out that, the limited amount of research on the topic recognises that co-opetition generally goes beyond the traditional competitive paradigm, recognising that competitive advantage is not only created individually by firms. Hence, the utility of the term co-opetition in consideration of industry clusters and their operation.

Clusters have become the focus of many different policy initiatives from around the globe over the past two decades. Business is frequently reliant on networks and networking within and between firms that belong to clusters, to support knowledge sharing and spillovers and to encourage the deliberate learning transferred from interaction with supporting institutions (Hilliard and Jacobsen, 2011). Channels through which knowledge spillover can occur include: public presentations; publications, cooperation; labour movement and sub-contracting (Malmerg and Power, 2005).

To enable co-operation and collaboration, trust has been identified as a fundamental characteristic of business networks which can significantly influence the quality of information and knowledge flows between business people (Murphy, 2006). Trust has also been identified as an important prerequisite for developing interorganisational relationships that facilitate interfirm knowledge exchange (Fukuyama, 1995). A primary motive for clustering is a response to a market opportunity between partners who would normally be in a competitive situation. This can lead to a volatile state of 'competitive collaboration' (Doz, 1996) where trust between competitors is even more important, because the risk of opportunistic behaviour is higher. Where organizations share resources and information openly with other participants they will generally seek to reduce opportunistic behavior through the mutual understanding and goodwill of parties. Then again, trust is not static; it is a dynamic process that evolves according to the development of the relationship (Clegg, 2000). Thus, once trust has been invested it is rational to rely on relationships where it has been developed (Fafchamps, 2001). Murphy (2006) points out that this can make it difficult however, for newcomers to intervene or 'tap into' established relationships where trust has been developed even if they have price, cost advantages or information.

Knowledge needs to flow between individuals, groups and firms in different locations, as well as within companies, in order to be used effectively. Therefore, it is important to ascertain what type of knowledge is valuable for both innovators and imitators and how is that knowledge transferred? 
New approaches have become necessary for sharing the value created in collaborative ventures and for promoting innovation. Porter's (2003) definition of innovation includes improvements in technology and better methods of doing things. Porter (1990) states that innovation can result from organisational learning as well as research and development, but that it always involves investment in developing skills and knowledge and sometimes physical assets and marketing efforts as well.

Knowledge sharing and trust building does not, of course, occur by itself. Mechanisms need to be in place to assist the sharing of information and ideas between individuals and they need to possess the skills whereby they learn about and from each other. As such, a range of strategies can support synergies in knowledge management to enhance learning within clusters such as interfirm support networks and working groups (Medcof, 1997). Hence, Persson, Sabanovic and Wester (2007) extended Porter's (1998) cluster model to include what they refer to as a 'positive social atmosphere' in clusters. Their study included 72 firms located within clusters in Sweden proposing the positive aspects of relationships in networks can foster trust and reduce risk through social exchange. Persson et als study identified that the top ranked benefits for firms in the clusters their study reported on were related to social relations and knowledge exchange as the major benefits that accrued from being located in a cluster.

Channels through which knowledge can spillover both within and outside of industry clusters include: public presentations; publications, cooperation; labour movement and subcontracting. Thus, Solvell, Lindqvist and Ketels (2003) maintain that firms that are active in regions that possess strong clusters tend to perform better. Clusters offer fertile ground for innovation and for developing competitive advantage for member firms. There are some key reasons as to why innovation tends to be connected with clusters which relate to the:

- Need for repeated and continuous interaction between related firms and specialised institutions (including research and education) and the

- Need for face to face contact to encourage the exchange and creation of new knowledge.
In this sense clusters and networks have the potential for the whole to be greater than the sum of its parts so that participating in networks can help even mature businesses come up with new ideas and creative combinations (Bessant, 2004).

Arino et al (2001) maintain that regardless of the size, form, or objectives underlying a cluster, one factor that serves to distinguish them from other forms of inter-firm behaviour is the need to establish relationships between the parties that make up the cluster. Further, they put forward that the quality of relationship enjoyed by parties within the cluster will depend upon the degree to which those parties have come to rely on trust in their dealings.

Knowledge sharing does not, of course, occur in isolation. Mechanisms need to be in place to assist the sharing of information and ideas between individuals and they need to possess the skills whereby they learn about and from each other. As such, a range of strategies can support synergies in knowledge management to enhance learning within strategic clusters such as interfirm support networks and working groups.

\section{CLUSTERS, COMPETITIVE ADVANTAGE AND INNOVATION}

Our recent study of the Dubai Free Zone clusters demonstrated that while businesses still seek competitive advantage from locating in cluster environments, it is not enough simply to be located near to similar businesses for a company to benefit from knowledge sharing and knowledge spillover opportunities to increase innovation. According to Porter's (1998) analysis, the potential benefits of doing business from a cluster are to:

- increase productivity

- drive innovation and

- stimulate new businesses

Clusters drive innovation because innovation is an outcome of knowledge interaction, and interaction is a social process involving people getting together and sharing ideas. When firms are located close to similar or complementary businesses, they have more immediate access to knowledge sharing through formal business networks (industry associations, public presentations, conferences) as well as less formal knowledge spillover opportunities, such as the 
potential to cooperate with the other companies, to benefit from the movement of labour between companies, subcontracting and outsourcing.

Nonetheless, it is not merely a factor of location that increases knowledge sharing and innovation potential. Cluster failure can occur when there are weak frameworks, facilitators lack strong networks, have insufficient budgets and neglect brand building which is crucial to continue to attract firms to the cluster. In order to manage innovation, businesses must learn to connect. Nabil Sakkab, a former Senior Vice-President of Research and Development at Proctor and Gamble expresses this succinctly: 'The future of $\mathrm{R} \& \mathrm{D}$ is $\mathrm{C} \& \mathrm{D}$ (connect with and develop) collaborative networks that are in touch with the 99 per cent of research that we don't do ourselves.' Companies cannot hope to do all their innovation in house - and it is only by tapping into broader networks that a business like Proctor and Gamble can retain its position as an innovative leader in product development. Similar stories can be heard at other companies, including IBM, Cisco and Intel, where links and connections are becoming as important as the actual production and ownership of knowledge. The ability of a business to connect effectively with other organisations will be a key innovation management strategy. Clusters, such as the Dubai free zones, can increase the attractiveness and the effectiveness of the cluster environments if they implement the right communication strategies for businesses provide robust knowledge sharing networks and invest appropriately in brand building for the cluster.

From an economic perspective The World Economic Forum's Global Competiveness Index (GCI) provides a useful basis for analysing the region's competitive strengths and identifying challenges that need to be addressed (Hanouz and Dusek, 2011). In this methodology, economies are ranked according to their level of development and three stages are identified: the factor-driven stage (1), the efficiency-driven stage (2) and the innovation-driven stage (3). The GCC classifications are outlined in Table 1.
Table 1: The GCC Countries in Transition

\begin{tabular}{|c|c|}
\hline Stage & Country \\
\hline $\begin{array}{l}\text { Stage } 1-\text { Factor driven }(37 \\
\text { economies) }\end{array}$ & India \\
\hline $\begin{array}{lllll}\begin{array}{l}\text { Transition } \\
\text { economies })\end{array} & \text { from } & \text { stage } & 1 & (24 \\
\text { to stage } 2 & & & & \\
\end{array}$ & Brunei \\
\hline $\begin{array}{l}\text { Stage } 2-28 \text { economies (efficiency } \\
\text { driven) }\end{array}$ & Malaysia \\
\hline $\begin{array}{l}\text { Transition from stage } 2 \text { to stage } 3- \\
18 \text { economies (innovation driven) }\end{array}$ & Oman \\
\hline $\begin{array}{l}\text { Stage } 3 \text { ( } 35 \text { economies) innovation } \\
\text { driven }\end{array}$ & $\begin{array}{l}\text { Australia, } \\
\text { U.K., U.S., } \\
\text { UAE }\end{array}$ \\
\hline
\end{tabular}

Source: Extract from Schwab (2011) The Global Competitiveness Report, World Economic Forum

The GCI methodology captures the interaction of 12 key drivers of competitiveness of an economy and recognises that different aspects will be important depending on a country's stage of development (Table 2). In the transition to stage 2 , basic requirements centring on cost advantages and efficiency enhancers are key areas of focus for improving competitiveness. Moving beyond this stage, innovation requirements become critical, with competitiveness based on the unique value of products and services produced.

Table 2: Twelve Key Drivers of Competitiveness

\begin{tabular}{|c|c|}
\hline Competiveness Dimensions & $\begin{array}{l}\text { Development } \\
\text { Stage }\end{array}$ \\
\hline $\begin{array}{l}\text { Basic requirements: } \\
\text { Institutions } \\
\text { Infrastructure } \\
\text { Economic environment } \\
\text { Health and primary } \\
\text { education }\end{array}$ & $\begin{array}{l}\text { Factor-driven } \\
\text { economies } \\
\text { (Stage 1) }\end{array}$ \\
\hline $\begin{array}{l}\text { Efficiency enhancers: } \\
\text { Higher education and } \\
\text { training } \\
\text { Goods } \\
\text { efficiency market } \\
\text { Labour } \\
\text { efficiency market } \\
\text { Financial } \\
\text { development market } \\
\text { Technological } \\
\text { readiness and adoption } \\
\text { Market size } \\
\end{array}$ & $\begin{array}{l}\text { Efficiency-driven } \\
\text { economies } \\
\text { (Stage 2) }\end{array}$ \\
\hline $\begin{array}{c}\text { Innovation factors: } \\
\text { Business } \\
\text { sophistication } \\
\text { Technological } \\
\text { innovation }\end{array}$ & $\begin{array}{l}\text { Innovation-driven } \\
\text { economies } \\
\text { (Stage 3) }\end{array}$ \\
\hline
\end{tabular}

Source: Hanouz and Dusek (2011). 
A number of institutional, demographic and structural barriers impacting the factors influencing competitiveness for Dubai can be identified, along with strategic responses and initiatives that will help to facilitate the region's competitive advantage. The focus essentially is on efforts to successfully move to a sustainable knowledge-based economy, one in which knowledge is acquired, created, disseminated and applied.

The World Bank's Knowledge Economy Index (KEI) provides a ranking for 147 countries and provides a measure of the extent to which an economy is likely to be able to support the effective use of knowledge for development (World Bank, 2012). A higher ranking (lower number) suggests an economy is better positioned. The KEI is based on measured performance scores across 4 dimensions: the economic incentive and institutional regime (EIR), education and human resources (EHR), the innovation system (I) and ICT providing more detail on the relative strengths and weaknesses facing individual countries in this area of the knowledge economy.

The EIR dimension reflects the extent to which an economy allows for efficient resource allocation and information flow. This spans a number of policy areas including the macroeconomic environment, labour markets and governance (which covers the legal system as well as the quality of bureaucracy). This provides the base on which the other dimensions stand. However, the four pillars interact and strategies/investments must, therefore, be balanced and coordinated.

The education and training system (as captured in EHR) needs to address the needs of a modern economy from primary through to vocational and tertiary education, in addition to lifelong learning. An effective innovation system (I) comprises business, consultants and research institutions that keep pace with new knowledge and technology while assimilating and adapting it to local needs, thus facilitating its diffusion. Foreign sourcing can often be critical in this area. Hence, industry clusters, which provide strong local and global business networks, can be viewed as an integral part of this process, providing mechanisms for firm interaction (Ewers and Malecki, 2010).
A modern information infrastructure underpins the communication, dissemination and processing of information and knowledge. ICT constitutes the basis for promotion of more advanced technologies and applications, central to a country's capacity to innovate and gain competitive advantage in terms of a knowledgebased economy (Dutta et al, 2007). The use of this general purpose technology facilitates product and process improvements and innovative activity across all sectors of an economy, including small- and medium-sized enterprises.

These competitive dimensions fit with the notion of constructed advantage, viewed as the 'new competitive advantage' relevant to knowledge based economies, as proposed by Cooke and Leydesdorff (2006, p. 10). They maintain that the dynamics of innovation and the capacity to exploit them requires interaction between the market, good governance, knowledge infrastructure and a supportive social and cultural environment. These factors can be found in effectively managed industry clusters. Having discussed the rationale for industry clusters in association with the potential for them to promote knowledge sharing, collaboration and innovation, discussion will now turn to Dubai and the study undertaken there.

\section{Dubai}

In a sense Dubai is a greenfield site where development has taken place at a breathtaking rate over a short period of time. This has arisen due to oil revenue, a base of few institutions and a rudimentary economy. Having experienced dramatic economic and social development the UAE is widely recognized as having a significant role to play within the global community of nations. Up until the recent global credit crisis the UAE labour market was generating approximately 300,000 new jobs each year with not enough locals to fill them. Dubai in particular ranks as one of the world's leading trading centres offering a gateway to a market of more than one billion people. Its economy has nearly tripled in size, to $\$ 34.5$ billion, in just a decade and it has established trading links throughout the AGCC, Iran and other neighbouring markets (Al Darwish, 2006). Dubai possesses a rapidly developing manufacturing sector and the port and airport facilities are unrivalled in the region in terms of size, flexibility and efficiency. 
However, the population itself is small, although since the discovery of oil over 40 years ago there has been rapid growth, particularly in the numbers of expatriates moving to the region over that period (Al Abed and Hellyer, 2001).

The 'cities' or clusters of Dubai have become a major drawcard for companies looking to invest and relocate in the region. Referred to as freezones, unlike other areas in Dubai, the clusters enjoy 100 foreign ownership, pay no taxes or import/export taxes and are largely free from the censorship applied elsewhere. Beginning in 2000 with Internet City, now there is Media City, Academic City, Health City, Industrial City, Children's City and many more to come.

The cluster model has been the basis for economic growth in the small United Arab Emirate state of Dubai since the first free zone, Jebel Ali Free Zone, was established in 1985. The free zone model - which includes tax advantages and other business incentives, as well as a cluster environment, has been so successful in attracting businesses and international investment, that in little over twenty years Dubai has grown from fishing village to a global business capital. The global financial crisis and a savage property bubble have wrought havoc, but the city state still has immense advantages that will return it to prosperity sooner rather than later.

Dubai's clustering strategy is very obvious driving through the city, the visitor is confronted by Internet City - where internet businesses operate - Media City - for media companies - and Dubai Knowledge Village - where universities operate - and there are many others besides as Dubai's clusters are both sizeable and obvious.

\section{METHOD}

The decision was made to interview key people (cluster facilitators, partner relationship managers and firm owners, managers or their representatives in three main firm categories) within two representative industry clusters based in Dubai. That is across a range of small, medium and large firms. The intention of the study was to uncover key themes arising from the interviews and compare the findings in order to answer the three questions posed at the beginning of this paper:
1. Why clusters as an antidote for growth and innovation?

2. What has been the approach to cluster development in Dubai?

3. What can cluster facilitators do to enhance knowledge sharing and collaborative innovation?

The sample firms included in the study were selected by the Partner Relationship Managers located within the two freezone clusters. A total of 18 interviews were undertaken, three each from across a range of small, medium and large firms within the two industry clusters (referred to as Cluster 1 and Cluster 2). Interviewees were asked some specific questions with regard to the cluster which related to their 'motives for participation and preferred cluster attributes' statements that were replicated from Perry's (2007) study on business environments and cluster attractiveness to managers. Once the interviews were conducted the results were coded using SPSS software.

\section{FINDINGS}

\section{Inside the Two Clusters}

Cluster 1 was established in 2003 and mostly focuses on trainers and consultants to support Dubai's move to a knowledge-based economy as part of the 2000 Dubai Strategic Plan. Cluster 1 is the only freezone with a management body to help companies position themselves in the market and interact with other firms. Three FZ clusters share marketing, HR and accounting services, while cluster 1 hosts companies involved in training and consultancy with the intention of complementing businesses in two other clusters that focus on media and IT. Cluster 1 competes with other freezones in Dubai which is seen as positive factor by their management as they see their strength in the services offered to businesses. There is a waiting list of companies wanting to move into Cluster 1 and a rigorous approval process which is based on financial strength, management competence and the like. Thus, many applications are rejected. Most firms that set up in Cluster 1 are from outside of the $\mathrm{UAE}$ and most have established clients in the GCC. They prefer to use Dubai as a base, encouraged by the general social and business environment there. 
Cluster 2: In the year 2000 approximately 100 IT related firms were given approval to operate in the new IT related Free Zone with another 350 firms awaiting approval. By mid-2004, the number of companies operating out of Cluster 3 had risen to more than 500 and by 2008 this number had risen to over 1000 with over 35,000 employees working in cluster 3 firms. In common with Cluster 1, Cluster 2 provides a 'one-stop-shop' environment for a variety of services required for setting up and running a business. Also in common with DKV there is a single point in DIC from which businesses can interact with different government entities such as the police, immigration, and postal authorities. DIC can assist in obtaining and authenticating vital documents, and in obtaining customs clearances, and a fast track immigration process is designed to ensure swift access to talent and resources. Companies can host independent web and e-commerce sites with a sister company, who provide hosting services from a secure data centre, with strong service level agreements and collaborative platforms. Also on offer are satellite broadcasting and Internet services, through a dedicated teleport, and in-house services such as event management and hospitality. Other support services operating within the community include food courts, banks, travel agents, car rentals, beauty salons, pharmacies, clinics, supermarkets and gymnasiums.

\section{Global markets}

As illustrated in chart 1 the majority (all but one) of the 18 cluster firms had global markets and export to the GCC countries and other areas of the Middle East (75\%), $17 \%$ to the US, UK, South Africa and Australia and 8\% to Europe (other than UK).

Chart 1: Where cluster firms are exporting

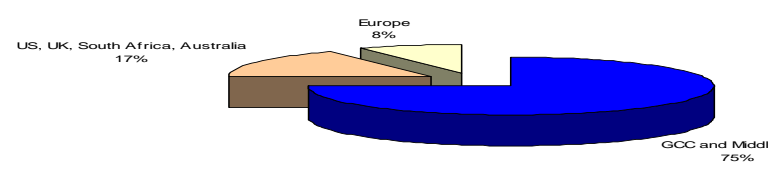

\section{Competition in the Cluster}

When asked about competition in the cluster, ten firms said their main competitors were located there and 9 said they were not. One firm said "Competition from other companies is good as we could get lazy. Better to have a small share of a larger pie than a large share of a small pie". Some interviewees thought that the location of more competitors in Cluster 1 would be beneficial and help to develop a clustered group of specialists, although competition was clearly evident in Cluster 2.

\section{Knowledge Flows in the Clusters}

In relation to knowledge flows there were some differences between the responses from interviewees located in Cluster 1 and those located in Cluster 2 as illustrated in charts 1 and 2. Interviewees were asked whether certain factors were motives for location within a cluster and preferred cluster attributes. For example in Cluster 1, 70\% of interviewees indicated that it was important that knowledge was shared among cluster firms, $60 \%$ said it mattered a lot that being in a cluster reduced the need for in-house provision of some activities and $39 \%$ said that it mattered a lot that the network provided opportunities to form new business relationships with other members as illustrated in Chart 1.

In Cluster 2 the situation was different with $50 \%$ of interviewees stating that it mattered a lot that other cluster firms were businesses they know and trust. $40 \%$ indicated that it was important that knowledge was shared among cluster firms and $40 \%$ that the network provided opportunities to form new business relationships with other members. A major difference from the Cluster 1, Cluster 2 interviewees was that only $10 \%$ indicated that it was important that being in a cluster reduced the need for in-house provision of activities.

One firm stated that not only does their staff get involved in the activities and training held within Cluster 1 but that they also invite their customers 
to come along as this helps to provide more impact and they can get the most out of it. Another said that "there is very little knowledge sharing happening in Cluster 2. Potentially there could be business opportunities coming from such networking - it is of course up to us to follow up leads.

\section{Chart 1: Knowledge Flows in Cluster 1}

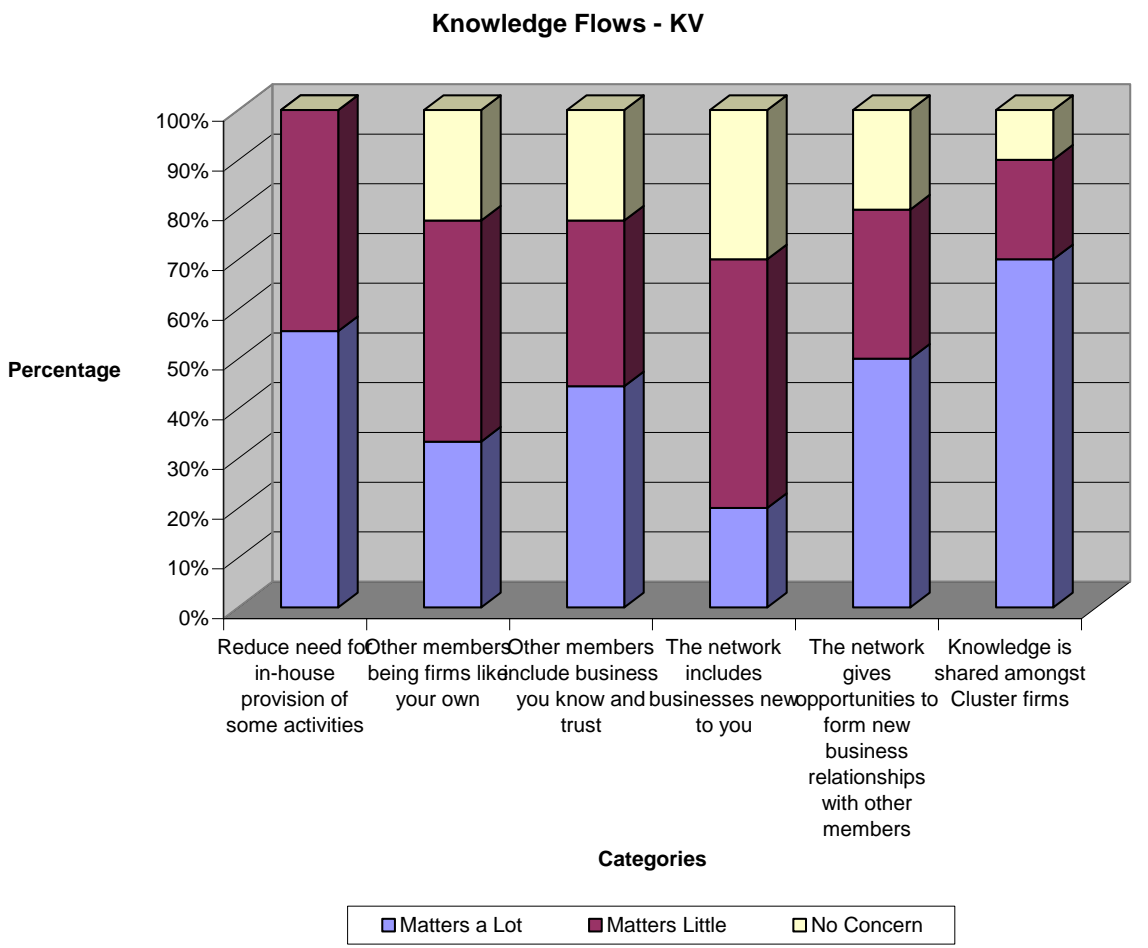

Chart 2: Knowledge Flows in Cluster 2

Knowledge Flows - DIC

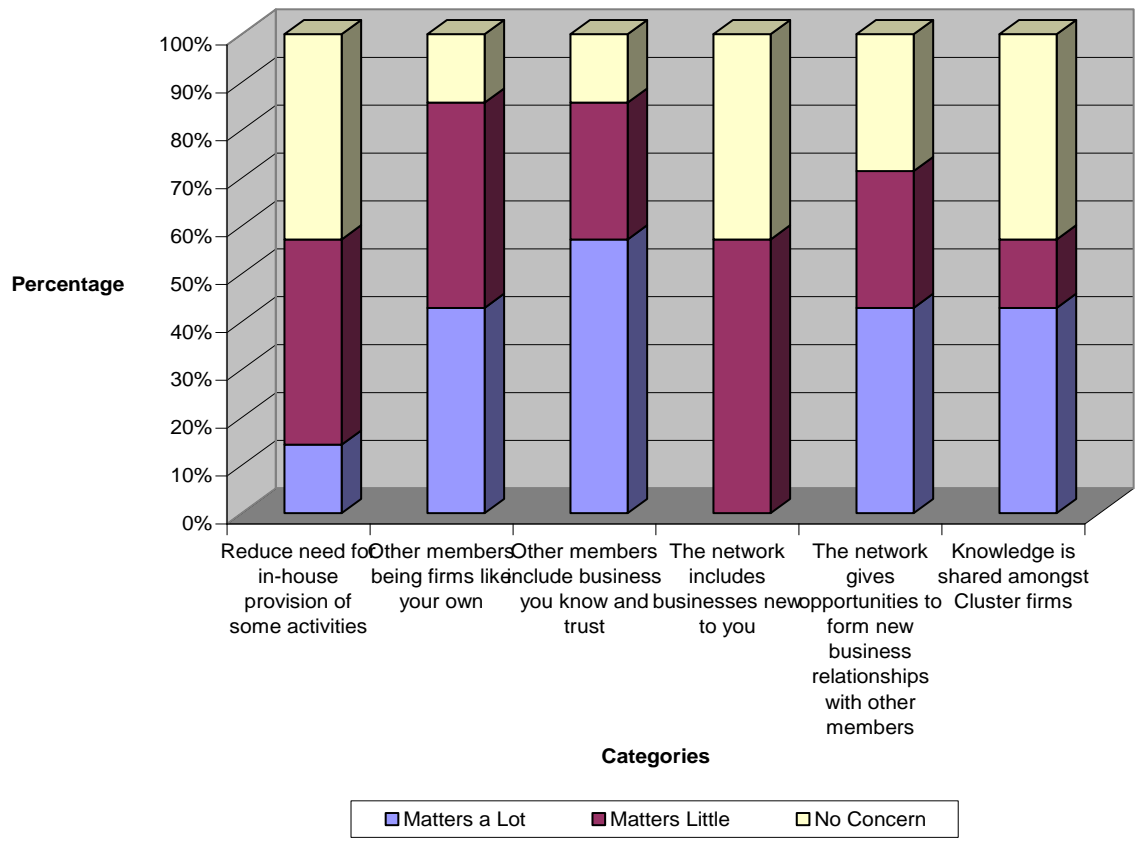




\section{Innovation in the cluster firms}

Innovation was identified as a critical area for the growth of organisations in the cluster firms. There were however differences between the two clusters though with regard to how innovation was perceived. For information-based organisations located within Cluster 1, innovation was related to having talent being able to provide creative solutions to clients, whereas for Cluster 2 organisations, innovation related to new products. Proximity in the cluster to clients, customers and competitors was cited as important for innovation for $50 \%$ of the Cluster 2 firms, whereas Cluster 1 firms identified the upskilling of staff, improved processes, strategies and tools as important for innovation which is most likely why cluster activities and networking were perceived as particularly important for Cluster 1 firms.

One firm said that "Cluster 1 networking encourages innovative thinking - activities have a positive effect - they are value adding and can also help to increase the role of individual organisations which is important in distinguishing Cluster 1 for what it does".

Another Cluster 1 firm said that innovation was very important as they "have to be different as there are 2000 companies offering training and development in Dubai".

When asked about the main factors influencing competitive advantage interviewees indicated these were mainly their own skills and competencies, other competitors and suppliers, support industries and labour markets affecting the clusters.

Turning to question 3, What do cluster facilitators do to enhance knowledge sharing and collaboration? The two clusters are considered in turn and a summary is provided in tables 3 and 4 .

In cluster one the relationship manager is responsible for most facilitation and support for potential firm collaboration. This includes holding cluster 'open-days', running events such as 'speed dating for business', holding breakfast meetings for members and other shared events and training as well as undertaking market research (such as issues faced by businesses operating in cluster 2 and in Dubai generally) which is fed-back to firm members. In addition, the Relationship Manager not only organises and hosts a series of networking events to encourage knowledge sharing and innovation, but also obtains sponsorship of such events from organisations in the region.

Cluster 2, the largest of the clusters there are several partnership managers in the partner relations group and they interface with cluster firms by location. Specifically, each partnership manager has 6 or 7 buildings to 'look after'. They organise events and networking through activities where all firms in a particular building are invited to breakfast to get to know other firms/employees in the same building. Also a quarterly event is hosted whereby prominent CEOs are invited to present and networking follows, plus a newsletter is circulated on a regular basis.

Table 3: Activities undertaken/supported by cluster facilitators

\begin{tabular}{|l|l|}
\hline Cluster 1 & $\begin{array}{l}\text { Open-days, speed dating for business, } \\
\text { breakfast meetings; } \\
\text { events/training; market research (such as } \\
\text { issues faced by businesses operating in } \\
\text { cluster 1 and in Dubai generally) which } \\
\text { is fed-back to firm members. Facilitator } \\
\text { not only organises and hosts a series of } \\
\text { networking events to encourage } \\
\text { knowledge sharing and innovation but } \\
\text { also obtains sponsorship of such events } \\
\text { from organisations in the region. }\end{array}$ \\
\hline Cluster 2 & $\begin{array}{l}\text { Largest of the 2 clusters - each } \\
\text { facilitator/partnership manager in the } \\
\text { partner relations group has 6 or 7 } \\
\text { buildings to 'look after'. Events include } \\
\text { networking through activities where all } \\
\text { firms in a particular building are invited } \\
\text { to breakfast to get to know other } \\
\text { firms/employees in the same building. } \\
\text { Also a quarterly event is hosted whereby } \\
\text { prominent CEOs are invited to present } \\
\text { and networking follows, plus a } \\
\text { newsletter is circulated on a regular } \\
\text { basis. }\end{array}$ \\
\hline
\end{tabular}

When comparing facilitation between the clusters, it is evident that there are some similarities and some differences between them. Both clusters have relationship managers and the tasks undertaken by them vary according to the size of the cluster. Cluster one firms experience closer relationships between cluster firms and the 
facilitators due to the greater frequency of events that are organised that provide more opportunities for interaction and the support provided by cluster members themselves in cluster one particularly means that they have a vested interest in seeing the cluster thrive and grow. The size of cluster two makes it more difficult for all member firms to interact with each other, with most networking occurring with firms located in their immediate vicinity.

\section{Table 4: Cluster Facilitation and knowledge sharing}

\begin{tabular}{|l|l|}
\hline Cluster 2 & $\begin{array}{l}70 \% \text { of interviewees indicated that it } \\
\text { was important that knowledge was } \\
\text { shared among cluster firms, 60\% said } \\
\text { it mattered a lot that being in a cluster } \\
\text { reduced the need for in-house } \\
\text { provision of some activities and 39\% } \\
\text { said that it mattered a lot that the } \\
\text { network provided opportunities to } \\
\text { form new business relationships with } \\
\text { other members. }\end{array}$ \\
\hline Cluster 3 & $\begin{array}{l}\text { 40\% of firms indicated that it was } \\
\text { important that knowledge was shared } \\
\text { among cluster firms and 40\% that the } \\
\text { cluster provided opportunities to form } \\
\text { new business relationships with other } \\
\text { members. Only 10\% of interviewees } \\
\text { indicated that it was important that } \\
\text { being in a cluster reduced the need for } \\
\text { in-house provision of activities. }\end{array}$ \\
\hline
\end{tabular}

Although both the Clusters reported here are at different life cycle stages and offer different products/services, it is evident that the role of Cluster facilitation is a vital one in order to bring member firms together and enhance relationship building/knowledge sharing processes.

As stated earlier, it is not enough just for a firm to be located in a cluster to assume that knowledge sharing will take place, as cluster failure may occur when there are weak frameworks, facilitators lack strong networks, have insufficient budgets

\section{CONCLUSION}

Clusters have emerged as an industrial organisational form that is recognised as having a more superior ability than single firms that operate in isolation to foster national economic development and growth. Cluster development was created with the aim of developing the knowledge-based economy in Dubai which focused on a variety of industry sectors including education and training, media and technology clusters.

The complexity of the innovation process leads many businesses to establish networks as such partnerships may provide vital access to new ideas, perspectives and business practices. As Bessant (2004) says no man is an island, and these days, few businesses are either. Companies operate in a complex web involving a host of different players, including suppliers, customers, competitors, regulators and collaborators. The challenge is said to no longer be about how to manage the business, but how to manage it within the wider context of networks. Networks are especially relevant in the context of innovation which is about knowledge and combining a wide range of knowledge elements to create something new. Thus, managing innovation is about bringing together different people and the knowledge they carry, and this involves building and running effective internal and external networks such as those developed through clusters.

The question (as identified by Mudambi, 2005) is how firms can move from a traditional cluster presence to the more active, knowledge-intensive innovation mode. It seems new paradigms are required in order to generate mechanisms that leverage innovation within clusters.

With regard to the findings from this study it appears that some of Porter's (1990) four diamond factors operate as expected by the model and some do not. Related and supporting industries through spatial proximity was a key issue in the clusters studied as indicated previously, particularly with regard to competition from other firms which was largely considered to be a positive factor. Demand conditions were also slightly different in Dubai to what might be expected from a 'traditional' cluster grouping as the majority of firms were exporting to places outside of Dubai so were not competing directly with firms in similar markets in most cases. Hence, it was evident that two out of four of the cluster factors identified by Porter (1990) were relevant in the Dubai freezone clusters. However, it is argued that the most relevant factor in this study was the modification 
to Porter's model which is referred to as the creation of a 'positive social atmosphere' (Persson, Sabanovic and Wester, 2007). This was evident both clusters.

The findings from this study indicate that more could be done to enhance innovation for the firms within both the clusters. They were managed very differently - with Cluster 1 firms experiencing more activities to bring firms together to share knowledge and ideas than the Cluster 2 firms. Many interviewees identified the need for more facilitated interaction to enhance the possibility of more innovation. So potentially, the message is that being in a cluster does not necessarily bring advantages for a firm. Although in the case of Dubai there are the obvious freezone benefits, which were considered to be a major source of competitive advantage, some firms were considering moving to another freezone with cheaper accommodation particularly if they were not experiencing the knowledge-intensive interactions within the 'positive social atmosphere' identified by Persson et al that lead to knowledge sharing and the desired collaborative innovation they desired with the other firms located in the cluster.

The importance of knowledge sharing within industry clusters has been discussed by many researchers (Connell and Voola, 2007; Niu, 2010; Tallman et al, 2004). It is suggested that it is now time for the clusters/cluster managers and facilitators themselves to share knowledge in order to place emphasis on this role and it's importance. In recognition of this gap a new Cluster Managers Club was established during the 2010 European Cluster Conference, as an interactive forum for cluster managers to gain inspiration and share new ideas.

To achieve a knowledge economy (KE) four pillars, or domains are identified, which underpin the knowledge-based development process. Although it is Pillar 3 that has been the focus of this paper the four include the:

1. Labour force

2. Information infrastructure

3. Innovation system (clusters are included here as this is how firms keep up with new knowledge and technology, tap into global networks/knowledge, adopt and diffuse technologies and this includes; firms research institutions, consultants and related personnel.

4. Economic and institutional regimes; markets, incentives and governance.

The need for attention to the four pillars is a key message for countries that need to coordinate at the regional level. Specifically, there is a need to identify strengths and weaknesses within each domain and develop strategies to address them. A number of variables and measures exist which can assist in the assessment of the performance of an economy. For example, the KEI (index) is a relative measure used by the World Bank, capturing the different measures of the four pillars.

Finally, it has been predicted that knowledge will become the economic commodity which will shape future businesses and individuals, with a 'top-down spill-over effect' occurring throughout the education system. To date, 'education cities' have been created in Dubai and in turn, they have attracted leading universities, colleges, training companies and business schools.

The industrial clusters in Dubai face a number of problems relating to a lack of trained human resource and marketing abilities and a need for improved coordination and linkages between different stakeholders among other things. Nonetheless, if these problems can be reduced or eliminated altogether, it is proposed that the specialised knowledge-bases being created through the industry clusters in Dubai will over time contribute to research and advancement in a number of fields and industries through the enhancement of knowledge sharing and collaborative innovation. It is proposed that such strategies will enhance the creation of local, nationally skilled workforces within Dubai, thus increasing competitive advantage. Consequently, industry clusters could eventually prove to be an antidote for knowledge sharing and collaborative innovation.

\section{REFERENCES}

Al Abed, I and Hellyer, P. (2001) United Arab Emirates, A New Perspective, Trident Press.

Al Darwish, R. (2006), Managing Human Resources as a Quality Driver: Empirical Study in the UAE, dspace.brad.ac.uk (accessed 12/3/07)

Arino, A, Torre, J., Ring, P. S. (2001), Roles Played by Relational Trust in Strategic Alliances, Research Paper, 432, IESE. 
Bessant, J. (2004) More than the sum of its parts. Financial Times, September 24, retrieved 7 March 2012, http://www.ft.com/intl/cms/s/2/6ce370f0-0e0b-11d9-97d300000e2511c8.html\#axzz1oOrOMZzM

Clegg, S. (2000), Trust as networking knowledge, Paper presented to the Trust in the Workplace Conference, University of Newcastle, November 2000 .

Connell, J. \& Voola, R. (2007) Strategic Alliances and Knowledge Sharing: Synergies or Silos, Journal of Knowledge Management, 11 (3), $52-66$

Cooke P. and L. Leydesdorff (2006) Regional Development in the Knowledge-Based economy: The Construction of Advantage, Journal of Technology Transfer, 31, 5-15.

Doz, Y.L. (1996), "The evolution of cooperation in strategic alliances: Initial conditions or learning processes?, Strategic Management Journal, Vo. 17 (Summer), pp. 55-83.

Dutta, S., Shalhoub, Z. and G. Samuels (2007) Promoting Technology and Innovation: recommendations to Improve Arab ICT Competitiveness, pp. 81-96 in The Arab World Competitiveness Report 2007, World Economic Forum, Geneva.

Ewers M., and E. Malecki (2010) Leapfrogging into the Knowledge Economy: Assessing the Economic Development Strategies of the Arab Gulf States, Tijdschrift voor Economische en Sociale Geografie, 101 (5), 494-508

Agglomeration and Industrial Linkages, China and World Economy, 16, 1, pp. 82-29

Fafchamps, M. 2001: Networks, communities and markets

in Sub-Saharan Africa: implications for firm growth and investment. Journal of African Economies 10, 109-42.

Fukuyama, F. 1995: Trust: The Social Virtues and the Creation of Prosperity. New York: The Free Press.

Hanouz, H. M and M Dusek (2011) Time of Opportunities: The Competitiveness Performance of the Arab World, pp. 9-41 in The Arab World Competitiveness Report 2011-2012, World Economic Forum, Geneva

Hilliard, R \& Jacobson, D (2011): Cluster versus Firm-specific Factors in the Development

of Dynamic Capabilities in the Pharmaceutical Industry in Ireland: A Study of Responses to Changes in Environmental Protection Regulations, Regional Studies, 45:10, 1319-1328

http://dx.doi.org/10.1080/00343404.2010.505916

Howarth, C., Gillin, M, \& Bailey, J. (1995), Strategic alliances, resource-sharing strategies for smart companies, Pitman Publishing, Melbourne.

Ionescu, D., (2005) 'Social Capital: A Key ingredient for Clusters in Post-Communist Societies', Ch 2 in OECD, Business Clusters, Promoting Enterprise in Central and Eastern Europe, OECD Publications, Paris

Ketels, C. (2003) 'The Development of the Cluster ConceptPresent Experiences and Further Developments', Paper prepared for NRW Conference on Clusters, Duisburg, Germany, December 5 .

Luo, Y. (2002), "Building trust in cross-cultural collaborations: toward a contingency perspective", Journal of Management, Vol. 28, No. 5, pp. 669-694.

Lynch, R. P. (1993), Business alliances guide: the hidden competitive weapon, Chichester: John Wiley.

Madhok, A. (1997), "Cost, value and for-seeing market entry model: the transaction and the firm", Strategic Management Journal, Vol. 18, No. 39-61.

Malmerg, A. and Power, D. (2005), How do Firms in Clusters Create Knowledge? Industry and Innovation, 12, 4, 409-431.

Medcof, J. W. (1997), "Why too many alliances end in divorce", Long Range Planning, Vol. 30, No. 5, pp. 718-32.

Montana, J.P. and Nenide,B. (2008) 'The Evolution of Regiona Industry Clusters and Their Implications for Sustainable Economic Development: Two case Illustrations', Economic Development Quarterly, 22 (4), November.

Motoyama,Y, (2008) 'What was New about the Cluster Theory? What Could it Answer and What Could it Not Answer?', Economic Development Quarterly, 22 (4), November, 353 363.

Madumbi, R, Multinational Firms and Clusters The Role of Knowledge Paper Presented at the International Conference on Innovation, Multinationals and Local Development, Catania, Sicilia, October 1, 2005

Murphy, J. T. (2006) Building Trust in Economic Space, Progress in Human Geography 30 (4 ) 427-450

Niu, K-H, (2010) Organizational trust and knowledge obtaining in industrial clusters, Journal of Knowledge Management, 14 (1), pp.141-155.

OECD, (2001) Innovative Clusters. Drivers of National Innovative Systems, Enterprise, Industry and services, OECD Publications, Paris

OECD, (2005), Business Clusters, Promoting Enterprise in Central and Eastern Europe, OECD Publications, Paris

OECD (2007) Competitive Regional Clusters: National Policy Approaches, Paris, OECD.

Parrilli, M., (2007), 'SME Cluster Development: A Dynamic View of Survival Clusters in Developing Countries', Palgrave and Macmillan, New York.

Persson, M., Sabanovic, A., Wester, H., (2007), Is Cluster Theory in need of Renewal? - Porter's Diamond Revised, Bachelor Thesis, from Kristianstad University/Department of Business Studies, http://www.essays.se/essay/ef726a54e9/

Porter, M. E. (1990). Competitive Advantage of Nations. London, Macmillan

Porter, M. (2003), Clusters and Regional Competitiveness, Recent Learnings, Paper presented at the Interntaional Conference on Technology Clusters, Montreal, Canada.

Porter, M. (1998) 'Clusters and the new economics of competition', Harvard Business Review, 76, 77-90.

Simmie, J (2008) The contribution of clustering to innovation: from Porter I agglomeration to Porter II export base theories, Ch. 2 in Karlsson, C. (ed.) Handbook of Research on Innovation in Clusters, Edward Elgar.

Solvell, O; Lindqvist, G and Ketels, C, (2003) The Cluster Initiative Greenbook, Gothenburg:VINNOVA.

Swann, P. Prevezer, M., and Stout, D. (eds), (1998) The Dynamics of Industrial Clustering: International Comparisons in Computing and Biotechnology, Oxford University Press, Oxford.

Tallman, S., Jenkins, M., Henry, N. and Pinch, S. (2004) Knowledge, clusters, and competitive advantage, Academy of Management Review, (29) 2, 258-71.

Watson, J (2011) Fostering innovation-led clusters A review of leading global practices, Economist Intelligence Unit Ltd, The Economist. http://www.managementthinking.eiu.com/sites/default/files/do wnloads/EIU-ATIC Report2 Web Revised.pdf

Wilhelm, M.M (2011): Managing coopetition through horizontal supply chain relations: linking dyadic and network levels of analysis. Journal of Operations Management 29(8)

World Bank (2009), Clusters for Competitiveness, A Practical Guide and Policy Implications for Developing Cluster Initiatives, February 2009, International Trade Department.

World Bank (2012) Knowledge Assessment Methodology, knhttp://web.worldbank.org/WBSITE/EXTERNAL/WBI/WBI PROGRAMS/KFDLP/EXTUNIKAM/0,,menuPK:1414738 p agePK:64168427 piPK:64168435 theSitePK:1414721,00.ht $\mathrm{ml}$

World Economic Forum (2011-2012) The Global Competitiveness Report, Geneva.

Yusuf, S. (2008) 'Can Clusters be Made to Order?', in Yusuf, S; Nabeshima, K and Yamashita, S (eds), Growing Industrial Clusters in Asia: Serendipity and Science, The World Bank, Washington DC. 